\title{
Afiches del Mayo Francés. Gráfica, autoría y alteridad sudamericana en 1968
}

\author{
Isabel Plante* \\ Universidad Nacional San Martín
}

\begin{abstract}
Resumen
Dada su relación con el Mayo francés, el Atelier Populaire constituye uno de los episodios más citado en relación a los cruces entre arte y política de los años sesenta. Sin embargo, tratándose de un episodio europeo, resulta significativa la centralidad que ciertos artistas sudamericanos tuvieron en la producción de esos afiches. Este artículo analiza la tensión entre los carteles firmados y aquellos producidos de manera anónima. En el contexto de la crisis que mayo del '68 significó para el campo artístico y su autonomía, se interpreta esa participación en términos de una alteridad que el tercermundismo identificaba con la producción cultural colectiva y politizada.
\end{abstract}

\section{Palabras clave}

Afiches del Mayo Francés; Autoría y alteridad; Artistas argentinos de París

\begin{abstract}
Given its relationship to the events of May 1968, the Atelier Populaire is one of the most frequently invoked imbrications of art and politics in the 1960s. The crucial role played by South American artists in the production of the studio's posters, however, has remained almost completely unexamined, perhaps because of the Atelier's collective nature. This paper analyzes several celebrated anonymous posters as well as others that were signed by individual artists. In the context of the crisis that May ' 68 represented for the autonomy of the artistic field, the participation of 'Others' lent an element of the contemporary discourse around Third World solidarity, in turn identifying the Atelier with the rise of a collective and radicalized cultural production.
\end{abstract}

\section{Key-words}

Posters of May 68; Authorship and otherness; Argentine artists of Paris

\footnotetext{
* Isabel Plante es Doctora en Historia del arte por la Facultad de Filosofía y Letras, Universidad de Buenos Aires. Investigadora de Consejo Nacional de Investigaciones Científicas y Técnicas (CONICET) en Instituto de Altos Estudios Sociales de la Universidad Nacional San Martín (IDAES-UNSAM) y docente en el Instituto de Investigación sobre el Patrimonio Cultural de la misma universidad (Tarea-IIPC). En 2011 obtuvo un Subsidio del Fondo Metropolitano de la Cultura, las Artes y las Ciencias para publicar el libro Argentinos de París. Arte y viajes culturales en los años sesenta (2013) editado a partir de su tesis doctoral. Desde 2015 integra la comisión directiva del Centro Argentino de Investigadores de Arte (CAIA).

Revista do Programa de Pós-graduação em Vol.15, n²/julho-dezembro de 2016 Brasília
ISSN-1518-5494 
"El arte entre paréntesis, la propaganda al primer plano" era el lema que se imponía poco a poco en París - afirmaba Christiane Duparc (1968a) a mediados de junio desde el semanario de izquierdas Le Nouvel Observateur. Luego de la asamblea sostenida entre artistas, críticos, estudiantes y galeristas en el anfiteatro Edgard-Quintet de la Université de la Sorbonne el 13 de mayo, las discusiones habían sido casi bizantinas hasta que algunos ex-alumnos de la École Nationale Supérieure des Beaux-Arts propusieron algo concreto: un grupo comenzaba a realizar afiches en el atelier Brianchon de litografía de esa escuela. El artículo de Duparc apareció en momentos del declive de las protestas, pero antes de las elecciones de fines de junio de 1968 en las que Charles De Gaulle obtuvo un apoyo mayoritario. ${ }^{1}$ En esa coyuntura, recapitulaba con cierta melancolía las actividades y discusiones desarrolladas en el taller ocupado por artistas y estudiantes.

"Atelier popular si, Atelier burgués no" fue el lema de este emprendimiento, que tuvo una actividad intensa y auto-organizada. Entre 13 de mayo y el 27 de junio, cuando la policía desalojó a los ocupantes, se llegaron a imprimir entre 2000 y 3000 afiches por día (Gervereau, 1988a), unos 120.000 impresos en total. En la asamblea diaria de las 19 horas, que podía reunir 100300 personas según la jornada, se sometían a votación las propuestas para afiches en función de dos criterios: si la idea política era ajustada y si estaba transmitida con eficacia. Con los carteles se hicieron pegatinas por las calles de París: compartieron las paredes con los célebres grafitis que, en ese final de los años sesenta, vislumbraban la playa por debajo del empedrado parisino y apostaban a que la imaginación tomara el poder.

Dada su intrínseca relación con el Mayo francés, el Atelier Populaire constituye uno de los episodios más citado en relación a los cruces entre arte y política durante los años sesenta. Sin embargo, hasta el momento los estudios no han indagado en que, tratándose de un episodio europeo, ciertos artistas sudamericanos tuvieron un lugar clave en la producción de los afiches del Mayo francés. Al menos tuvieron ese lugar en los testimonios de los protagonistas franceses: tanto el mencionado Guy Rougement como el artista Gérard Fromanger y el crítico Gérald Gassiot-Talabot le adjudicaron a los integrantes del Groupe de Recherche d'Art Visuel (GRAV) en particular y a los artistas sudamericanos en general un rol fundamental en el seno del Atelier Populaire. En efecto, sabemos que tanto Julio Le Parc y Francisco Sobrino dos de los seis integrantes del GRAV - como Hugo Demarco, Antonio Seguí y Rómulo Macció -todos artistas argentinos residentes en París - tuvieron una participación activa en la producción de afiches en apoyo a la movilización que se inició como una protesta estudiantil en la Universidad de Nanterre y escaló

1Durante la primera semana de junio se produjeron negociaciones con diversos gremios y la movilización masiva comenzó a menguar. El 7 de junio La Nación anunciaba que la mayor parte de los huelguistas volvían al trabajo.

Revista do Programa de Pós-graduação em Arte da VIS Vol.15, n²/julho-dezembro de 2016 Brasília
ISSN-1518-5494 ISSN (versão eletrônica):2447-2484 
a una huelga de 9 millones de trabajadores que paralizó Francia por dos meses.

Menos conocidos resultan hoy los carteles litografiados que, a partir de una iniciativa llevada adelante por una serie de galerías de arte parisinas en ese mayo de 1968, produjeron y firmaron una treintena de artistas, entre los cuales también se encontraba Antonio Seguí. La autoría y la circulación, tanto en ventas o pegatinas como en reproducciones de libros publicados ese mismo año, constituyeron motivos de confrontación entre quienes imprimieron carteles en apoyo a la revuelta de mayo. En este artículo sostenemos que la crisis de la figura aurática del artista y su obra, que puede seguirse en diversas escenas culturales de los años sesenta, se articuló aquí con la emergencia de la figura de un sujeto tercermundista, concebido como un sujeto colectivo y politizado, que en Francia se configuraba como una alteridad de gran productividad cultural y política.

Durante esos años que median entre el triunfo de la Revolución cubana de 1959 y el golpe de Estado que derrocó a Salvador Allende en Chile en 1973, se consolidó la convicción de que la Historia cambiaba de escenario y se trasladaba al Tercer Mundo (Gilman, 2003). América Latina condensó nuevos sentidos ligados a un tercermundismo que festejaba esas "voces colectivas" que por primera vez se hacían escuchar sin la mediación de los intelectuales. En este contexto, sostenemos que el Atelier Populaire constituye uno de los ámbitos privilegiados para rastrear los vínculos entre resistencia cultural y extranjería.

Este artículo analiza algunos de los afiches del Mayo francés: confronta los producidos de manera anónima y atribuidos a los artistas argentinos del Atelier con aquéllos que, impresos fuera de Beaux-Arts [École Nationale Supérieure des Beaux-Arts], fueron firmados por sus autores. Rastrea la participación efectiva de los artistas argentinos en el diseño e impresión de carteles para analizar el problema de la autoría y su espesor geopolítico en relación con la configuración de una comunidad cultural latinoamericana de París. Nuestra reflexión incorpora el estudio de los dos libros editados en 1968 que reprodujeron buena parte de estos afiches e inscribieron perspectivas diferentes para abordar su eficacia política y su vínculo con los parámetros tradicionales del arte: Mai 1968, affiches (París, Tochou, 1968) y L'Atelier Populaire présenté par lui-même (París, Usines Universités Union, 1968).

A lo largo de estas páginas intentaremos demostrar que los artistas argentinos de París mencionados vieron en el Mayo Francés la oportunidad de protagonizar una movilización masiva y de batallar codo a codo con estudiantes y trabajadores identificados, en muchos casos, con la figura del Che Guevara. Los cinetistas probablemente encontraron además un modo de 
radicalizar la desmitificación del arte que venían promoviendo desde inicios de la década, aunque al producir afiches tuvieran que sacrificar su inscripción en la abstracción geométrica. Los carteles eran, como los múltiples cinéticos, artefactos visuales de tiradas generosas y alto impacto visual pero habitaban la calle con mayor naturalidad que las obras cinéticas. A su vez, en el contexto de la crisis que mayo del '68 significó para el campo artístico y su autonomía, la participación de los artistas argentinos fue interpretada en relación con ese sujeto latinoamericano que el tercermundismo identificaba con una producción colectiva y politizada.

\section{¿Una impronta sudamericana en el Atelier Populaire?}

Los primeros carteles se imprimieron utilizando la piedra litográfica del taller tomado, pero rápidamente Guy Rougement, quien trabajaba en un taller de serigrafía profesional, introdujo la técnica serigráfica para facilitar el trabajo y ampliar las tiradas (Bertrand Dorleac, 2000). ${ }^{2}$ La serigrafía implicaba ciertas limitaciones plásticas si no se contaba con la infraestructura para utilizar el método de la insolación. ${ }^{3}$ Para la impresión de los carteles, se solicitaba a los artistas que hicieran un dibujo simple con goma arábiga sobre la seda del bastidor serigráfico. En el diseño se debían evitar las medias tintas y prever la impresión a un color. El anonimato de los autores - no sólo en el cartel finalizado sino también al momento de discutir la propuesta - era un punto fundamental pues se consideraba que la firma abonaba el individualismo y era uno de los parámetros medulares del mercado de arte (Gervereau, 1988b: 180).

El Atelier Populaire fue una actividad colectiva, anónima y auto-organizada con una circulación informal de numerosos artistas y estudiantes, de modo que resulta improbable lograr un listado ajustado de participantes y roles. Por lo tanto, la impronta sudamericana en los afiches colectivos del Mayo francés no resulta estrictamente comprobable. Pero el lugar que le asignan tanto los protagonistas franceses como investigaciones más recientes (Wlassikoff, 2008) merece ser tomado en serio para rastrear la participación efectiva de algunos artistas y el modo en que articularon sus respectivas trayectorias con esta experiencia de producción colectiva, y también para indagar en las representaciones de lo latinoamericano que se configuraron en Francia hacia fines de los años sesenta.

En un artículo de junio de 1968 en la revista francesa Opus International, el crítico Gérald Gassiot-Talabot se refería a "la actitud ejemplar del GRAV en el atelier populaire" (Gassiot-Talabot, 1968a). Años más tarde, Rougement

\footnotetext{
${ }^{2}$ Los primeros afiches serigráficos fueron del 15 y 16 de mayo.

${ }^{3}$ La insolación consiste en la exposición de la pantalla serigráfica a la luz, de modo que la emulsión fotosensible que previamente se aplicó sobre ella fragua y, al lavarla, se desprende de aquellas partes en las que no incidió la luz, quedando la máscara del dibujo. Recién en junio instalaron un pequeño laboratorio donde pudieron trabajar con fotos y con el proceso de insolación que permiten reutilizar las sedas y trabajar a varios colores, así como conseguir ilusión de tridimensionalidad.
} 
sostenía en una entrevista que "los latinoamericanos tenían por cultura, por tradición, este tipo de dibujo muy simple que pusieron al servicio de estos afiches y que probablemente les dieron el tono" (Gervereau, 1988b). Por su parte, Fromanger afirmó en otra entrevista que la serigrafía era casi desconocida en Francia, excepto por la gente del GRAV y otros cinetistas extranjeros y activos en París como Yacov Agam, Hugo Demarco, Carlos CruzDiez o Jesús Rafael Soto (Gervereau, 1988a).

En efecto, los artistas mencionados por Fromanger realizaban "múltiples serigráficos" muchas veces producidos por el cubano Wifredo Arcay, quien trabajó para la galería Denise René y sus artistas desde mediados de los años cincuenta. ${ }^{4}$ Pero más allá de lo ajustadas que puedan resultar las apreciaciones de los testimonios franceses sobre el aporte sudamericano, ¿qué podemos afirmar respecto de la presencia de estos artistas en el Atelier Populaire? Sabemos que los cinetistas Hugo Demarco y Julio Le Parc fueron arrestados el 7 de junio en camino a la fábrica de Renault de la localidad de Flins, a unos 40 kilómetros de París y luego fueron expulsados de Francia (Plante, 2013), de modo que solo pudieron haber frecuentado Beaux-Arts antes de esta fecha. ${ }^{5}$ Según el testimonio de Le Parc, con Francisco Sobrino habían ido a la Sorbona todos los días a ver qué ocurría y se enteraron de la toma del taller litográfico de Beaux-Arts (Le Parc, 1995). Esto pudo haber tenido lugar durante los diez primeros días de la toma del taller, ya que el 23 de mayo Le Parc viajó a México con motivo de su exposición en el Palacio de Bellas Artes y regresó los primeros días de junio. En este sentido, y no sin picardía, Antonio Seguí recuerda que Le Parc volvió ansioso por participar de la revuelta; por eso fueron a Flins, uno de los últimos focos rebeldes, y "cayeron como chorlitos". 6

Le Parc afirma que propuso una serie de afiches, algunos fueron aprobados por la asamblea y se imprimieron. El artista recuerda que "Dar forma visual a las consignas para que fuesen atractivas en las calles o en las fábricas era todo un desafío. Había que inventar imágenes que golpeasen" (Le Parc 1995). Mediante la abstracción geométrica y el cinetismo se podían inventar efectos visuales potentes que desestabilizaran las percepciones de personas de hablas distintas, pero no era viable transmitir ideas políticas precisas ni críticas puntuales al gobierno francés. Miembros del GRAV, Le Parc y Sobrino tenían experiencia en trabajo grupal y seriado; esta vez se abocaron a la tarea colectiva pero dejaron de lado la tendencia artística a la que adscribian.

\footnotetext{
${ }^{4}$ Arcay también expuso su propia obra geométrica en esa galería. Su taller de serigrafía era visitado por artistas diversos, de modo que resulta dudosa la idea de que era una técnica desconocida en Francia.

${ }^{5}$ Luego de un arresto de 48 horas se les dio diez días para que abandonaran el país. A pesar de las gestiones de la embajada argentina ante las autoridades francesas, ambos fueron expulsados de Francia por participar de las protestas, pero pudieron regresar en noviembre de ese mismo año.

${ }^{6}$ Entrevista de la autora con Seguí, 8/5/2008. 
Renovaron la apuesta del cinetismo por llegar al "gran público" ahora movilizado y ampliado a los trabajadores (Plante, 2011).

Los integrantes del GRAV conocian bien la técnica serigráfíca y tenían el hábito de trabajar el blanco y negro para sus trabajos ópticos. De modo que pusieron su experiencia, enraizada en la abstracción geométrica, al servicio de la retórica figurativa de los afiches de mayo. En su catalogación, Michel Wlassicoff (2008) también afirma que los latinoamericanos hacian punta con las propuestas. Menciona a los cinetistas Le Parc, Demarco y Sobrino y también a los neo-figurativos Rómulo Macció y Antonio Seguí, a quienes les atribuye conjuntamente cuatro afiches conocidos como Nous sommes le pouvoir, La lutte continue, Capital y Pouvoir populaire. Aquí es importante destacar que si bien uno de los afiches más célebres se le atribuye a Macció (Saiegh,1998), Le Parc insiste en mantener el anonimato de la autoría de estas imágenes.

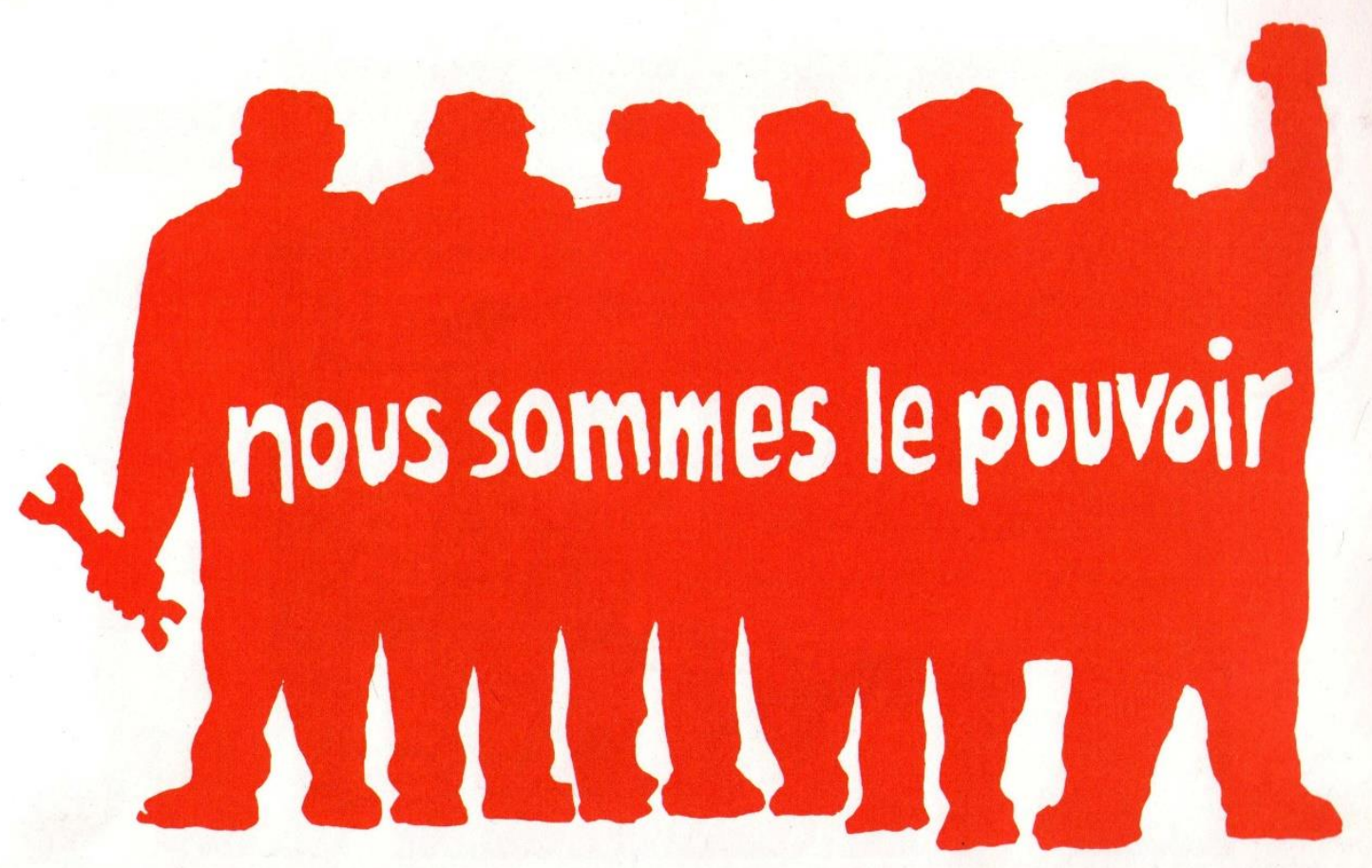

Fig. 1. Afiche atribuido a los artistas argentinos del Atelier Populaire (1968). Serigrafía s/ papel, $51 \times 45 \mathrm{~cm}$.

En su ajustada cronología, Wlassicoff data al afiche Nous sommes le pouvoir como producido el 21 de mayo, el mismo día en que se difundió el volante titulado "Atelier bourgois: non. Atelier poulaire: oui" donde declaraban:

Hay ahora diez millones de huelguistas en Francia. Los participantes del Atelier Populaire van hacia las fábricas ocupadas, los depósitos y las canteras a fin 
de escuchar de los trabajadores en huelga cómo continuar la lucha de la que ellos son vanguardia.

No es un trabajo de laboratorio; cada uno, trabajador o estudiante, extranjero o francés, viene a participar con entusiasmo de la producción de afiches. Los obreros vienen a proponer consignas, a conversar con los artistas y los estudiantes, a criticar los afiches producidos o difundirlos afuera. (Atelier Populaire, 1968: 9-10)

El afiche mencionado representa un grupo de figuras masculinas (se distinguen seis cabezas y once piernas) que, gracias al uso del pleno de color, tienen una apariencia compacta y unificada. Los identificamos como trabajadores unidos sólidamente en lucha en razón de dos atributos: en uno de los extremos, una mano lleva una llave francesa y en el otro extremo, un puño se enarbola en alto. En momentos en que la protesta alcanzaba su mayor extensión, la leyenda recortada "Nosotros somos el poder" en blanco sobre este "cuerpo colectivo" rojo parece reforzar la voluntad de los participantes (extranjeros) del Atelier de desmarcarse de la figura aurática del artista individual, e identificarse con el colectivo de los trabajadores en lucha. ${ }^{7}$

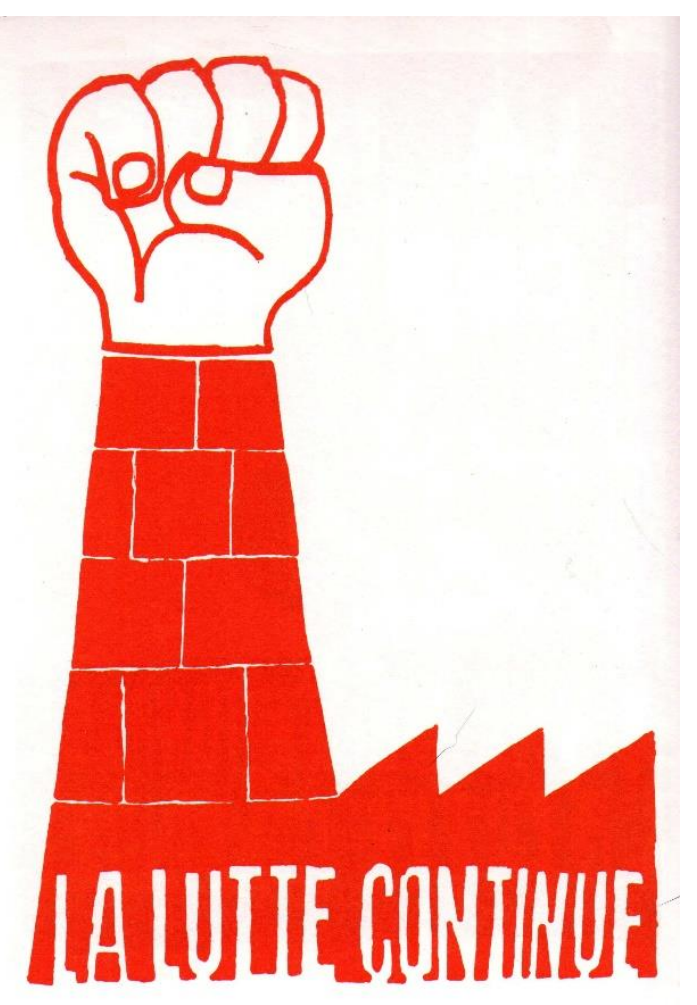

Fig. 2. Afiche atribuido a los artistas argentinos del Atelier Populaire (1968). Serigrafía s/ papel, $50 \times 76 \mathrm{~cm}$

${ }^{7}$ A comienzos de junio se hizo otra versión con la leyenda "La lutte continue", impreso en azul. 
El cartel con la leyenda La lutte continue combina el sintético perfil de una arquitectura fabril con su chimenea, por la que en vez de humo sale un gran puño apretado en alto como símbolo de la lucha de los trabajadores. Ha sido fechado como posterior a los acuerdos del 27 de mayo firmados por la CGT francesa, dirigida por el comunismo, producto de las negociaciones del presidente Charles De Gaulle que consiguieron desagregar la huelga masiva y generar un paulatino retorno al trabajo (Wlassicoff, 2008). En este convenio - conocido como los acuerdos de Grenelle - que los huelguistas de la fábrica de automóviles Renault rechazaron, se contemplaba, entre otras cuestiones, el pago de los días de huelga. En momentos en que, a pesar de la continuidad de los disturbios, algunas empresas retomaban la actividad, la consigna "La lucha continúa" arengaba por la persistencia en la discusión de la agenda y las estrategias políticas.

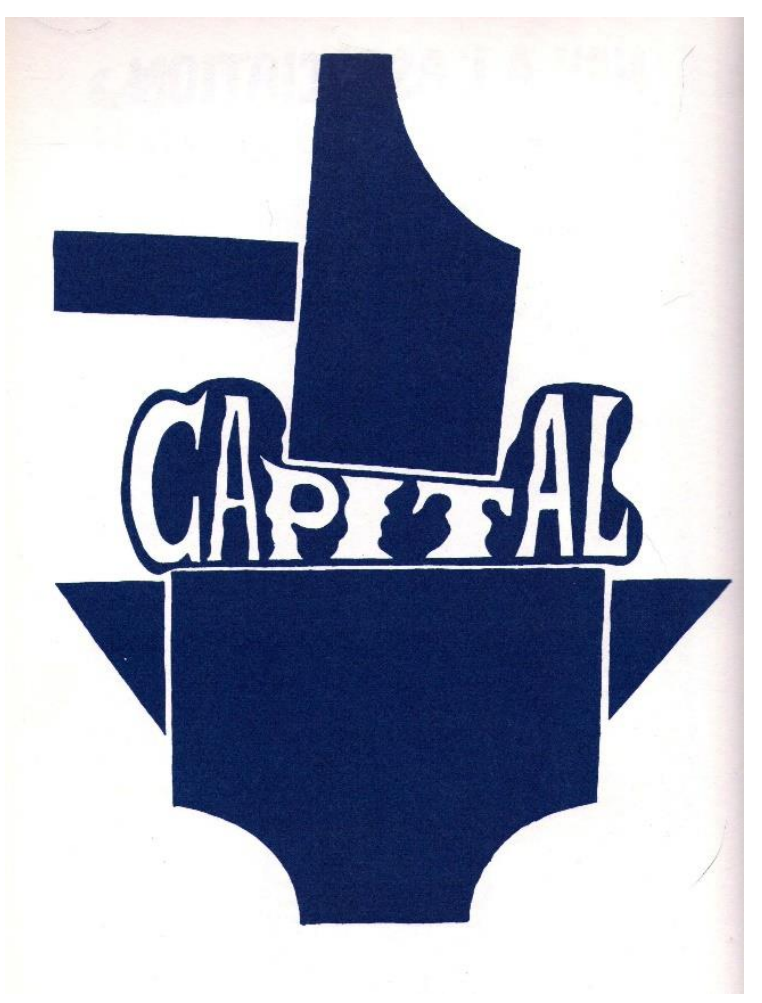

Fig. 3. Afiche atribuido a los artistas argentinos del Atelier Populaire (1968). Serigrafías impresas en dos medidas : $50 \times 76$ y $80 \times 120 \mathrm{~cm}$.

El cartel impreso en color azul conocido como Capital también fue realizado en referencia a las negociaciones de Grenelle. Alude al mundo del trabajo fabril por medio de una iconografía tradicional del trabajo de herrería: la representación de una maza y su correspondiente yunque. Aquí lo que se golpea y se deforma es la palabra "Capital", dibujada con una tipografía ajena a la estandarización tanto del diseño moderno como de la producción en cadena. La imagen pone a la vista que las fuerzas productivas tienen la 
capacidad de modelar el capital, invita a imprimirle cambios contundentes hasta transformarlo en otra cosa.

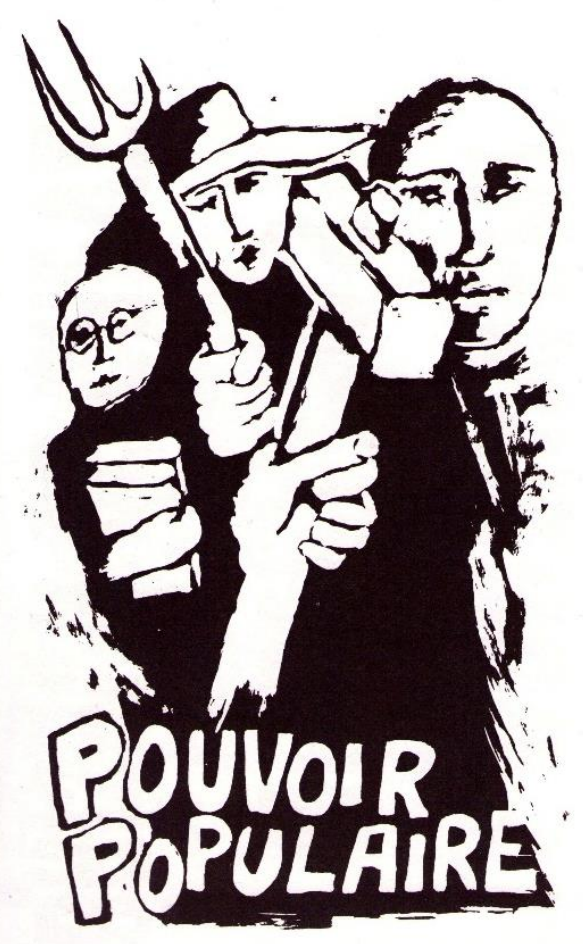

Fig. 4. Afiche atribuido a los artistas argentinos del Atelier Populaire (1968). Serigrafía s/ papel, $67 \times 115 \mathrm{~cm}$

Por último, el cartel que lleva la leyenda "Poder popular" respondía puntualmente a la consigna "gobierno popular" enarbolada por el Partido Comunista y la CGT franceses en la masiva manifestación que estas entidades organizaron el 29 de mayo a lo largo de los Grands boulevards, en París (Wlassicoff, 2008). Con menor grado de síntesis visual que los otros carteles comentados aquí, representa a diferentes tipos de trabajadores identificables por sus atributos: maza, horquilla y sombrero de ala ancha, libro y anteojos. Obreros fabriles, campesinos y universitarios aparecen confraternizados e identificables por igual con un poder popular que había paralizado toda Francia.

\section{Adscripción estética y materialidad de los carteles}

Los talleres de grabado de Beaux-Arts no estaban equipados para imprimir con serigrafía. Las mesas que se utilizaron no estaban acolchadas, con lo cual, al momento de estampar, la seda del bastidor serigráfico no siembre hacía buen contacto con el papel y por ende el plano de color podía presentar alguna falta. Sumado al ritmo afiebrado de impresión y al bajo gramaje del papel utilizado, 
los posters estaban llenos de imperfecciones. En este sentido, Elizabeth Guffey (2015) afirma que mientras en la Sorbona tomada los estudiantes colgaban verdaderos posters con retratos en offset de Lenin, Mao o el Che, en el Atelier Populaire se crearon anti-posters. Allí fueron desatendidos cincuenta años de desarrollo de procedimientos técnicos orientados, por ejemplo, a ajustar la imagen fotográfica, a planear cuidadosamente el espacio entre caracteres y estandarizar tipografías. Dada la urgencia y las condiciones de producción, se apostó a imágenes más precarias que los posters profesionales, pero eficaces a la hora de seguir el ritmo acelerado de los eventos diarios y convocar a la crítica y la acción política. Si los afiches, como tipo específico de pieza gráfica, se caracterizan por su eficacia en la comunicación visual, si "deben lograr contacto instantáneo" (Barnicoat, 1972), establecer expectativas en relación con determinadas conductas $u$ ofrecer una voz unificada a un gran número de personas (Guffey, 2015), a pesar de su rusticidad las serigrafías salidas del Atelier Populaire pueden ser considerados afiches por derecho propio.

A la hora de explicar las características formales de esta producción colectiva, cuya estética resulta bastante homogénea, Gassiot-Talabot se refería a la influencia de los afiches cubanos realizados desde comienzos de la década. Según el crítico, "numerosos artistas sudamericanos presentes en Beaux-Arts" reivindicaban esos carteles revolucionarios que en París se difundían en Opus International, la revista qué él mismo co-dirigía (Gassiot-Talabot, 1968a). Por cierto, el objetivo de propaganda política emparentaba a los afiches del Aterlier Populaire con aquellos producidos y difundidos por instituciones nacidas de la revolución cubana como la Comisión de Orientación Revolucionaria, la Casa de las Américas o la Organización de Solidaridad de los Pueblos de Asia, África y América Latina (Léger, 2013): en ambos casos se tendía a optimizar la comunicación y generar identificación, o bien con un Estado revolucionario en consolidación, o bien con la crítica a un régimen político supuestamente representativo, mediante consignas contundentes e imágenes condensadas 0 alusivas que se desmarcaban del realismo didáctico de la afichística de la República popular China y de la Unión Soviética (Guffey, 2015: 184-214).

Sin embargo, ciertos rasgos formales y materiales de los afiches del Atelier Populaire los hacen fácilmente diferenciables de los carteles cubanos. En las serigrafías a un color producidas para acompañar y dar voz a la movilización masiva del Mayo Francés se utilizaron caligrafías manuscritas y figuras realizadas a mano alzada. Aunque se imprimieran con métodos que no implicaban necesariamente el gesto manual, los afiches mostraban esta marca de lo realizado a mano. Ese aspecto entre endeble y empático de las figuras representadas se potencia con la economía de recursos materiales y formales. En su monocromía y su iconografía de ribetes caricaturescos, los afiches realizados en el Atelier Populaire carecen del componente pop que hace de 
los carteles cubanos piezas tan atractivas en términos de colorística e impacto visual, y los inviste de cierto aspecto publicitario. Pero más allá de estas diferencias, al igual que buena parte de los críticos latinoamericanos (Serviddio, 2013: 59-60), Gassiot-Talabot encontraba un lugar clave para los carteles cubanos, en tanto producción cultural renovadora y popular que había logrado aunar la creación artística a los intereses colectivos.

Entre las referencias estilísticas de los afiches del Atelier Populaire, GassiotTalabot también apuntaba el Push Pin Studio, el estudio neoyorkino de diseño gráfico fundado en 1954 por Milton Glaser, Seymour Chwast, Reynold Ruffins, y Edward Sorel que se destacó por el uso de ilustraciones y citas gráficas en una propuesta ecléctica de diseño que se apartaba de los cánones modernos tales como la estandarización tipográfica y la síntesis formal. El crítico francés recordaba que en 1967 se había organizado una exposición del Push Pin Studio en París, donde muchos podrían haberlos visto (Gassiot-Talabot, 1968b: 87). Sin embargo, si bien cierta frescura dada por el uso predominante del dibujo suelto aproxima la heterogénea producción del Push Pin Studio a la del Atelier Populaire, tanto la abundancia de recursos y referencias gráficas como inserción profesional de la firma norteamericana establecían un parte aguas entre ambas experiencias. (Chwast, 2004) El acabado apresurado y la materialidad precaria de la producción parisina poco tenían que ver con el diseño e impresión de publicidades culturales y comerciales del estudio neoyorkino.

En el Atelier Poulaire coincidieron estudiantes con poca experiencia y artistas de adscripciones estéticas diversas. En el caso de los cinetistas argentinos, podría pensarse que en momentos de su mayor éxito en términos de mercado y de convocatoria de público, estos afiches fueron un modo de desmarcarse de una estética cinética que parecía vincularse cada vez más con el mundo de la industria cultural, la decoración de interiores y las identidades corporativas. Estos artistas dejaron a un lado el acabado de aspecto industrial de sus múltiples cinéticos y aplicaron a la iconografía del Atelier Populaire algo de ese espíritu lúdico que tan atractivo resultaba para el amplísimo público de las exposiciones de arte cinético (Plante, 2011).

\section{El problema de la autoría}

Como ya se indicó, Antonio Seguí experimentó el clima de trabajo en BeauxArts, pero para él no resultó una experiencia alentadora. El Atelier fue, en buena medida, una iniciativa del grupo de la Jeune Peinture (Jóven Pintura), compuesto por artistas comunistas, maoístas, anarquistas e izquierdistas sin filiación definida que coincidían en una figuración crítica de alusiones políticas expresas (Parent y Perrot, 1983). Según Gérard Fromanger, integrante de la Jeune Peinture, en el Atelier Populaire se despreció a quienes firmaban sus litografías 0 afiches, y las decisiones tomadas en las asambleas diarias no se 
discutían; éstas eran "muy ordenadas, muy morales" (Gervereau, 1988a). El anonimato y el trabajo conjunto contribuyeron -en opinión de Fromanger- a que los afiches tuvieran cierta uniformidad estilística.

Por el contrario, Seguí asevera que la Jeune Peinture gravitaba sobre las decisiones de la asamblea: "los afiches que querían exponer eran los que hacían ellos. Se oponían a lo que presentaban otros". ${ }^{8}$ En esta línea, Wlassikoff (2008) señala a Pierre Buraglio y Gilles Aillaud (ambos de la Jeune Peinture) como líderes a cargo del control de los contenidos y slogans. Diariamente, una primer asamblea definía los contenidos y en la reunión de la tarde se presentaban los bocetos para carteles. La toma de decisiones mediante asamblea, que se planteaba como ejercicio de democracia directa, se ajustó cada vez más a las premisas del maoísmo. Para Seguí, este modo de trabajo resultó autoritario, una suerte de doctrina del anonimato digitada por unos pocos. Que modificaran una propuesta suya fue - según recuerda - el hecho que suscitó su alejamiento del Atelier Populaire.

Esto no significa que Seguí no estuviera interesado en la política ni en los acontecimientos de mayo de 1968. El artista no sólo formó parte del comité de apoyo a la toma de la Maison de l'Argentine de la ciudad universitaria de París, realizada el 21 de mayo por parte de un grupo de estudiantes, sino que también pintó en ese edificio, a la par del artista chileno Roberto Matta, un mural que caricaturizaba al dictador Juan Carlos Onganía, presidente de facto de la Argentina desde junio de 1966 (Plante 2013: 208-209).

Seguí también participó en la iniciativa, por parte de la Galerie du Dragon, de editar afiches inspirados por los movimientos de mayo para aportar ayuda financiera a la Union Nationale des Étudiants de France. A diferencia de los carteles del Atelier Populaire, se trataba de litografías firmadas por sus autores, que se involucraban según el modelo tradicional de 'notables' en apoyo a una causa. A su vez, otros 23 marchands firmaron un texto en el que se comprometían a facilitar la realización de carteles solidarios y a venderlos en provecho de la lucha. Por esta razón, posiblemente, fueron más de 30 los artistas que firmaron afiches (Violeau, 2008). ${ }^{9}$ Según el testimonio de Seguí, los integrantes del Atelier Populaire "le hicieron un escándalo a la Galería del Dragón. Los acusaron de burgueses", a pesar de que las estampas no se expusieron en la galería sino que se adhirieron sobre las paredes en la vía pública al igual que las serigrafías del Atelier..$^{10}$

\footnotetext{
${ }^{8}$ Entrevista con Seguí, ya citada.

${ }^{9}$ Matta, Hélion, Alechinsky, Cremolini, Pommereulle, Pichette y Jorn, entre otros.

${ }^{10}$ Entrevista con Seguí, ya citada. Por otra parte, la idea inicial del Atelier era vender las estampas.
} 

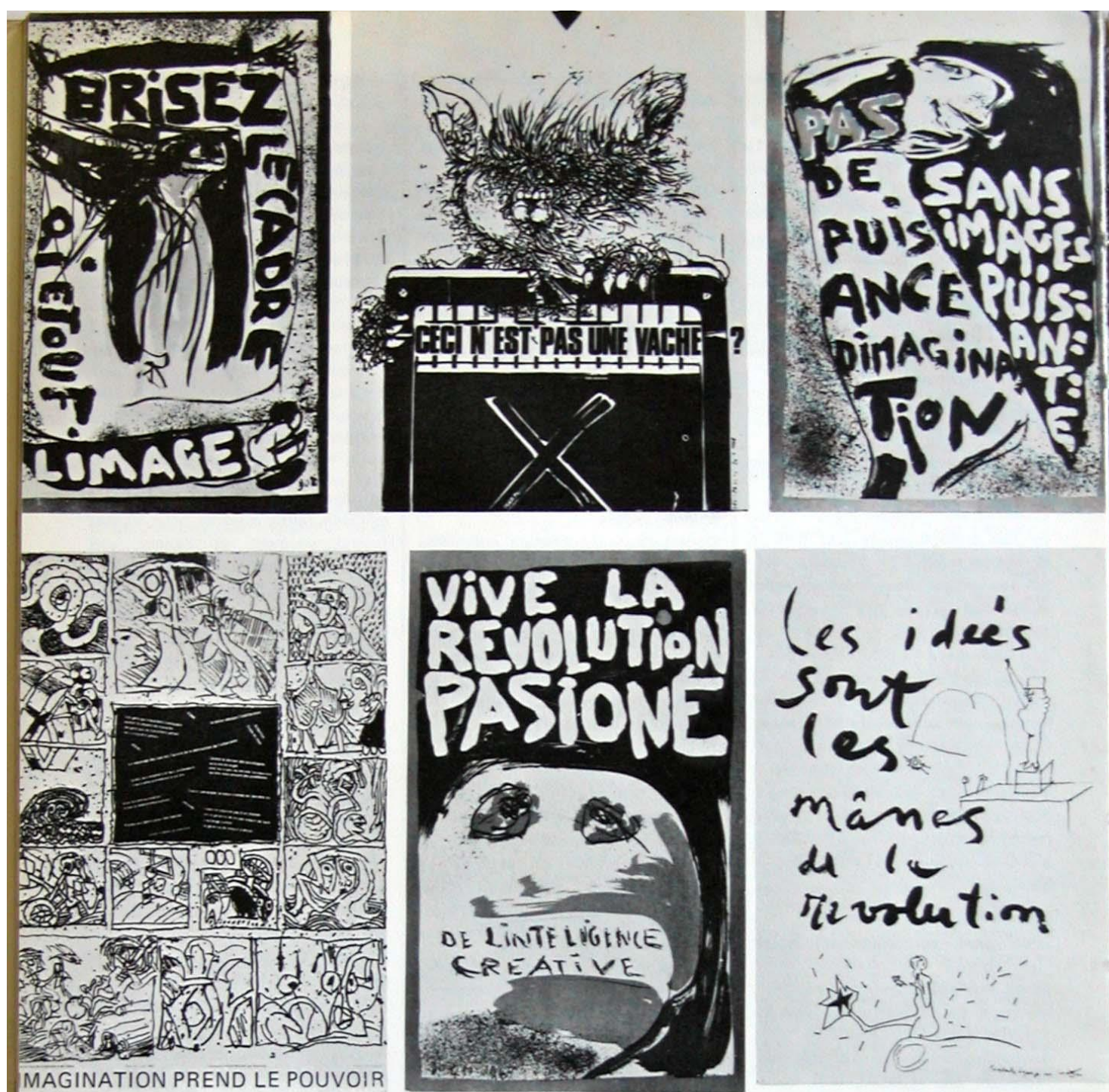
de 14 revolution
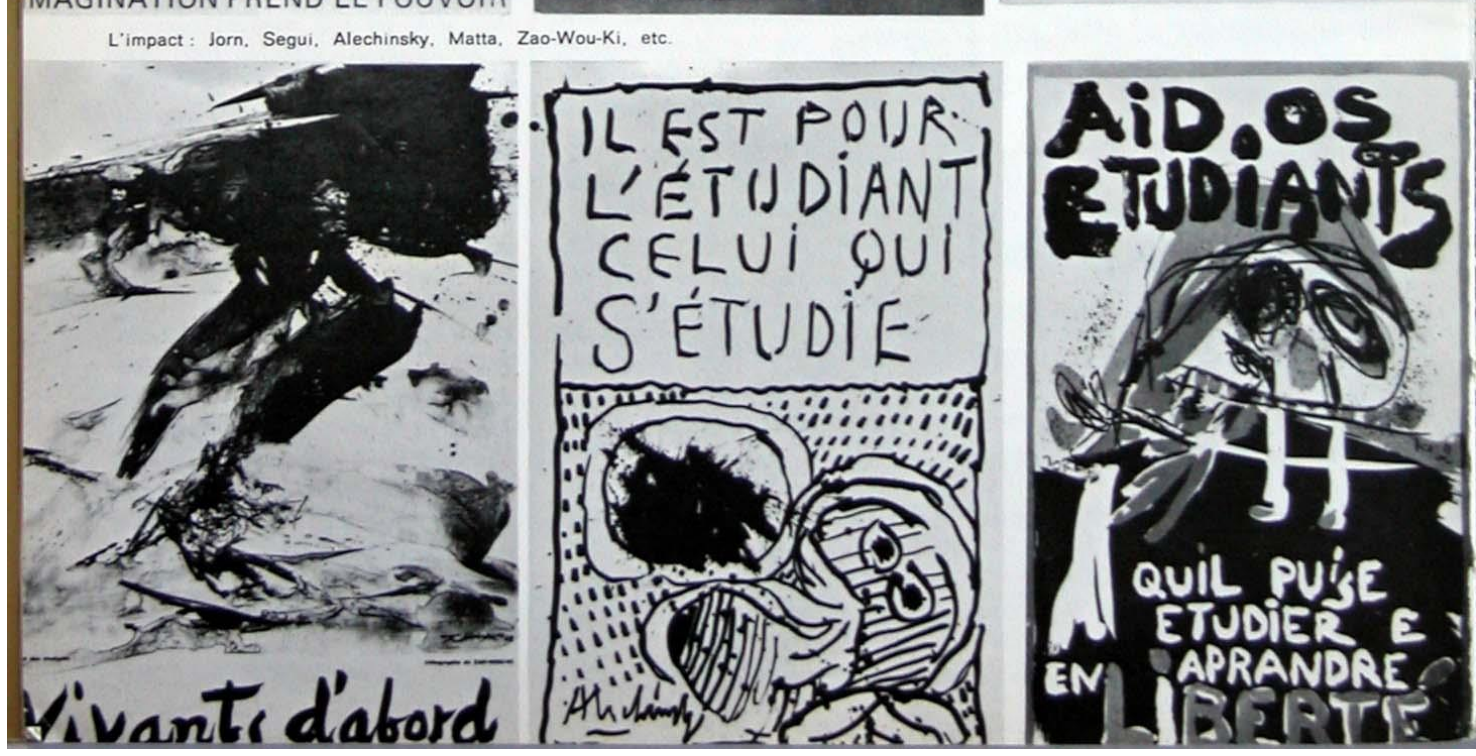

Fig. 5. Afiches firmados reproducidos en Opus International n. 7, Paris, juin 1968. Matta, Hélion, Alechinsky, Segui y Jorn, entre otros. 
La rivalidad entre las concepciones colectiva e individual de los carteles aparecía con claridad en el comentario de Gassiot-Talabot sobre la publicación de la editorial Tchou, que a fines de junio de ese mismo año reunió buena parte de los carteles de mayo: Mai 1968, affiches. ${ }^{11}$ En sus 35 láminas a colores de gran formato $(48 \times 32 \mathrm{~cm})$, el libro reproducía algunos afiches anónimos del Atelier Populaire (entre ellos dos de los atribuidos a los argentinos), y también una serie de afiches firmados por Alechinsky, Asger Jorn, Bona-Pieyre de Mandiargues, Costa, Cremolini-Gaudibert, Dufour-Butor, Matta, Milhaud, Seguí y Silva-Cortázar, así como caricaturas de Effel, Sempé y Tim. En sus primeras páginas se aclaraba la intención documental pero también la selección operada:

El rol de un editor, más allá de la actualidad inmediata de la cual da cuenta la prensa, consiste en asegurar la supervivencia de documentos espontáneos e irremplazables.

Nuestra selección ha descartado los afiches que pudieran transmitir un llamado a la violencia y aquéllos que tuvieran un carácter difamatorio de privados 0 funcionarios públicos. ${ }^{12}$

Gassiot-Talabot argumentaba que en este libro se mezclaban los "afiches artísticos" con los anónimos a pesar de sus diferencias técnicas y plásticas, "sin hablar de las condiciones políticas de su aparición". En este sentido, esa "lujosa edición mundana" contrastaba con otra realizada poco después de cerrada la experiencia y le resultaba "de una indecencia insostenible" (GassiotTalabot 1968 b: 87). El crítico se refería a L'Atelier Populaire présenté par luimême (El Atelier Populaire presentado por sí mismo, Paris: Usines, Universités, Union, 1968), un librito decididamente más modesto. De formato pequeño $(17 \times 10 \mathrm{~cm})$ e impreso a un solo color, reproduce un número mucho mayor de afiches colectivos (87 contra 23 en el libro de Tchou) junto con las proclamas producidas desde el Atelier Populaire al calor de los acontecimientos de esos meses. En este sentido, constituía un documento menos confuso, tal como afirmaba Gassiot-Talabot, pero también menos abarativo de la producción afichística de esos meses. Por otra parte, su aspecto poco atractivo (probablemente fruto de la escasez de recursos) lo hacía menos afín a la fetichización y consumo de los carteles.

Desde unos años antes venía teniendo lugar una suerte de revival del afiche, cuyo primer boom se remontan a fines del siglo XIX. Tanto en el mundo capitalista como en Cuba o China (aunque en otra escala), ese auge estuvo ligado a la migración de los carteles desde el espacio público hacia el consumo privado puertas adentro. Buena parte de la producción sicodélica e incluso de los afiches con retratos estrellas de cine o de íconos revolucionarios -

11 Tchou también publicó una compilación de transcripciones de los grafittis que se inscribieron sobre las paredes durante el Mayo francés. Les murs ont la parole : mai 68. Paris: Tchou, 1968.

12 Mai 68. Affiches. Paris: Tchou, 1968, p.2. 
artefactos visuales de bajo costo- resultaban clave en la construcción identitaria de muchos jóvenes (Guffey, 2015). En París florecieron los negocios de posters, donde se ofrecían al público imágenes muy variadas que también podían verse en los bouquinistes a lo largo del Sena. ${ }^{13}$ En este contexto, el Atelier Populaire devolvía al afiche a la calle; no resulta forzado pensarlo como una estrategia artística para devolver al espacio público (y la opinión pública) unos carteles múltiples y colectivos con consignas claras e imágenes empáticas.

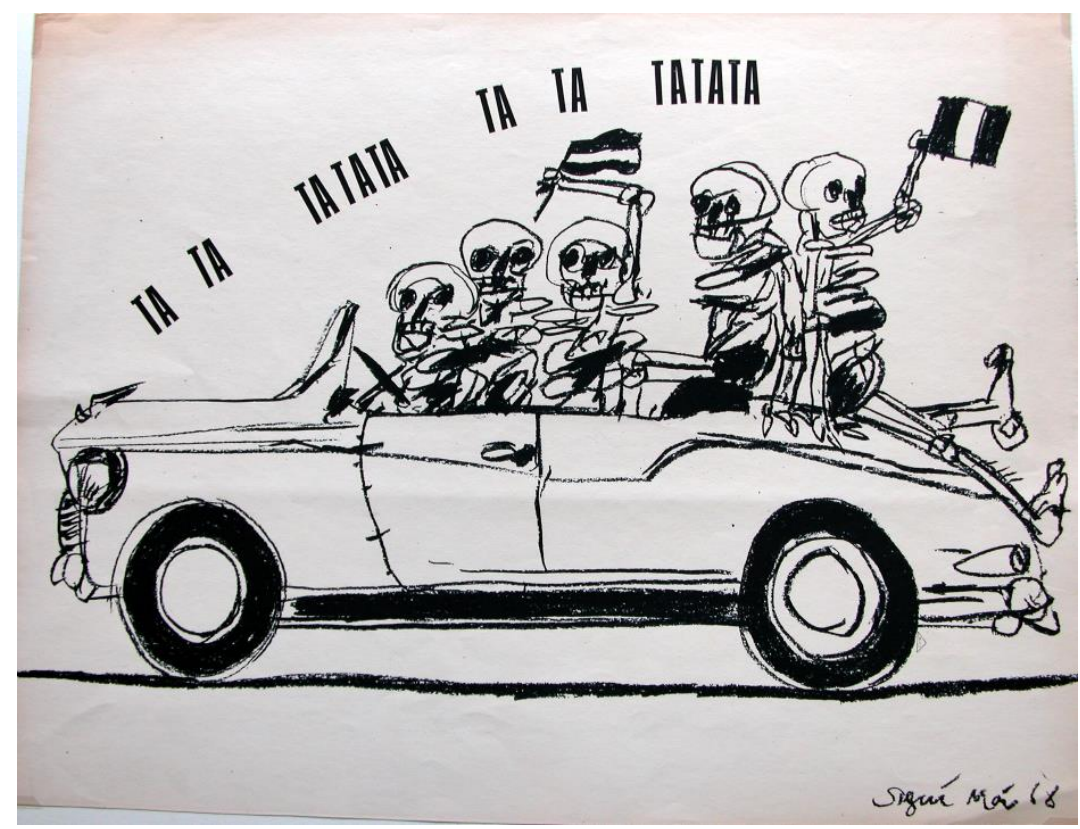

Fig. 6. Antonio Seguí, Ta Ta Tatata Ta Ta Tatata (1968), litografía sobre papel. Bibliothèque de Documentation Contemporaine, París.

Entre los afiches firmados del Mayo francés, el libro de gran formato editado por Tchou incluyó uno de los dos carteles litográfícos firmados y fechados por Antonio Seguí en mayo de 1968 que conocemos: Ta Ta Tatata Ta Ta Tatata. De trazo suelto e impresas en negro sobre papel blanco, al igual que muchas de las obras de Seguí de este período, ambas estampas incorporan textos en letra de molde. Representadas como esqueletos, las figuras de ambos afiches recuerdan las conocidas estampas de José Guadalupe Posada. ${ }^{14}$ Así como el grabador y caricaturista imbuido de la tradición mexicana mostraba personajes de distintos estratos sociales como calaveras postulando que la muerte igualaba a ricos y pobres, Seguí utilizaba este recurso para representar las autoridades gubernamentales francesas, en un cartel, y la policía en el otro.

${ }^{13}$ Le livre rose du hippy (1968) fue posiblemente la primer traducción al francés sobre la cultura hippie anglosajona; una suerte de compendio sicodélico con citas de Timothy Leary, Allen Ginsberg, Gary Snyder, Aldous Huxley y Bob Dylan, entre otros, que se combinaban con reproducciones de mandalas, pinturas y posters vibrantes de Rick Griffin, Peter Max, Martin Sharp o el duo Hapshash and the Coloured Coat.

${ }^{14}$ Seguí había vivido en México entre 1958 y 1960. 
En Ta Ta Tatata Ta Ta Tatata un automóvil descapotable similar a los utilizados para trasladar a De Gaulle en los desfiles oficiales, lleva cinco esqueletos sentados sobre los asientos y el baúl. Dos de ellos agitan pequeñas banderas. El sonido rítmico de la bocina traducido a escritura junto con la leve inclinación del auto hacia adelante remite a una suerte de desfile triunfal protagonizado por figuras que si bien parecen animadas, se muestran como difuntos. A pesar de la pompa, el régimen gaullaino se revelaba inanimado.

El otro afiche de Seguí, que lleva la leyenda "On ne matraque pas l'imagination", muestra cuatro esqueletos levantando sendas cachiporras en una de sus manos. En el centro del círculo que delinean los cuerpos descarnados de estos policías se ve un quinto esqueleto, sin armas. El texto ("la imaginación no se aporrea") evoca algunos de los grafitis que se escribieron en las paredes de París durante las jornadas de mayo de 1968, como el conocidísimo "la imaginación toma el poder". Además, podría pensarse que el artista introdujo otro guiño a la cultura latinoamericana. En esta consigna resuena el lema "las ideas no se matan" de Domingo Faustino Sarmiento. En el prefacio de Facundo o civilización y barbarie en las pampas argentinas (1845), Sarmiento decía haber escrito durante su huída a Chile en pleno período rosista "on ne tue point les idées" sobre una pared, frase que atribuía al francés Hippolyte Fortoul. Esta cita apócrifa, cuyo sentido político residía -para Ricardo Piglia (1980)- más en el uso de la lengua francesa que en su contenido, era aludida por Seguí en el contexto del Mayo francés. En esta estampa, la barbarie aparecía encarnada por las fuerzas del orden galas, quienes dominaban la lengua francesa a la perfección pero pretendían imponer sus convicciones a fuerza de cachiporra.

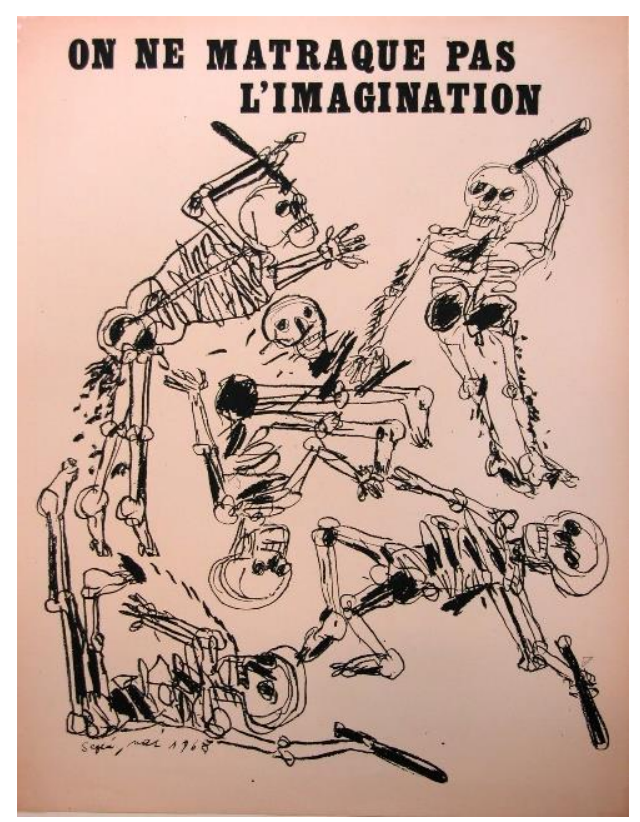

Fig. 7. Antonio Seguí, On ne matraque pas l'imagination (1968), litografía sobre papel. Bibliothèque de Documentation Contemporaine, París 


\section{La crisis de la autonomía artística y la alteridad}

Unos meses antes de las revueltas de mayo, en febrero de 1968, en las páginas de una revista francesa de actualidades la periodista cultural Christiane Duparc (a quien ya mencionamos al comienzo), afirmaba que los latinoamericanos copaban París y que el día que decidieran irse todos juntos, los parisinos se sentirían solos, tristes y aburridos. En teatro, Jorge Lavelli, Copi y Gerôme Savary; en literatura, Julio Cortázar y Ernesto Sábato; en artes visuales, Carlos Cruz-Diez, Jesús Rafael Soto, Julio Le Parc, Wifredo Lam, Roberto Matta, Sergio Camargo, Mario Di Teana, Luis Tomasello y "cantidades de brasileños, venezolanos y argentinos. El arte cinético es 80\% ellos" (Duparc 1968b: 46). La nota rescataba los relatos de la llegada a París y la tenacidad para hacerse un lugar en la ciudad-luz. La periodista terminaba por resaltar más que sus reconocidas calidades artísticas, algunas de las costumbres de sociabilidad de estos inmigrantes, como el asado dominguero en el atelier de Le Parc al que solían asistir sus colegas argentinos.

Lo que nos gusta de esta sociedad sudamericana de París, no es sólo que sus miembros hayan logrado imponerse en la batalla del espectáculo, de la literatura o de las artes; sino también que se trata de un islote cultural donde aún prevalecen valores pre-capitalistas como la amistad, la solidaridad, la afectividad, la virilidad, devenidos raros en la sociedad de consumo donde, bien o mal, intentamos nadar. Estos indolentes que no tienen horarios, estos campesinos obstinados e infatigables decididamente tienen algo para enseñarnos. (Duparc 1968b: 51)

Más allá del sabor a primitivismo del comentario de Duparc, la imagen que ofrecía ("Ios latinoamericanos están por todos lados") tenía fundamentos. Hacia fines de los sesenta el flujo de inmigrantes alcanzaba cifras mucho mayores que las de los veinte años anteriores. ${ }^{15}$ Las cantidades siempre fueron restringidas si se las compara con las de los inmigrantes de África del Norte, por ejemplo. Pero la inmigración latinoamericana estaba constituida de un porcentaje sensiblemente mayor de intelectuales y artistas, lo que le otorgaba mayor prestigio y visibilidad (Rolland; Touzalin, 1994). Su presencia fue percibida por las élites culturales y políticas francesas con cierta amplificación y valoración positiva.

Esta imagen que se tenía en Francia de los latinoamericanos como una comunidad cultural relativamente homogénea (entre pre-capitalista y revolucionaria) no era ajena a la configuración, por parte de los intelectuales del nuevo continente, de un latinoamericanismo que se insertaba en la solidaridad tercermundista en general y en particular respecto de la experiencia revolucionaria cubana (Gilman, 2003). Por cierto, en la politización masiva de la juventud francesa fueron centrales una serie de identificaciones con dos

15 Si en 1946 eran unos 3800 los latinoamericanos residentes en Francia, para 1968 eran más de 9800. La cifra se duplicó después de los golpes militares en Chile y Argentina. 
figuras: el trabajador y el militante colonial (o guerrillero). En palabras de Kristin Ross (2002), durante mayo y junio de 1968 éstas fueron representaciones ficcionales y teóricas, y a la vez interlocutores en un diálogo frágil, efímero e históricamente específico.

Tanto la independencia de Argelia como el arribo de Fidel Castro al poder en La Habana focalizaron la atención del anti-imperialismo francés y contribuyeron a la emergencia de una mitología del guerrillero revolucionario alrededor del Che Guevara y al progresivo reemplazo de la URSS por el Tercer Mundo en el imaginario revolucionario (Jameson, 1997). ${ }^{16}$ En este sentido, si bien el mayo francés no fue una protesta anti-colonial, el repertorio antiimperialista jugó un rol clave en el proceso de politización de los estudiantes. La agenda se 'nacionalizó' con rapidez, de modo que la lucha internacional contra el imperialismo norteamericano devino en lucha doméstica contra la "sociedad de consumo" y el orden gaullista (Bertrand, 2008). Y en esta contienda, la identificación francesa con el Tercer Mundo y el horizonte revolucionario jugó un rol clave. Carlos Fuentes, escritor mexicano y cronista del Mayo francés, ${ }^{17}$ ofreció una imagen fraternal de esta identificación:

Secularmente enajenados y excéntricos por y ante la imagen universal del Hombre blanco, burgués, cristiano, capitalista y racional, hoy nos identificamos con los hombres que, desde el antiguo centro, se proclaman tan excéntricos y enajenados como nosotros y en nosotros se reconocen. Dios murió, y con él su privilegiada Criatura occidental. El Hombre ha muerto, pero los hombres están vivos. La excentricidad radical -la revolución- es hoy la única universidad concebible. (Fuentes, 1971)

Alrededor de mayo de 1968, el pensamiento de Herbert Marcuse ganaba popularidad internacional. Frente a la libertad aparente que ofrecía la sociedad industrial avanzada, la alternativa estaba -señalaba en El hombre unidimensional (1964)- en aquellas personas no integradas a esa lógica férrea. Los extranjeros, junto con los explotados, los perseguidos de otras razas o los desocupados, constituían una de las pocas esperanzas frente a los productos de los medios masivos. Por su parte, Jean-Claude Passeron, colega y cómplice de Pierre Bourdieu en esa época, recuerda:

Después de 1968, existió por momentos el deseo, en relación con la teoría de los micropoderes de Foucault, de adjudicarle todo a la cultura de la resistencia, a la capacidad de grupos o clases dominadas de dar la espalda, de desviar y,

${ }^{16}$ El término mismo "Tiers Monde" había sido acuñado en 1952 por el demógrafo francés Alfred Sauvy en las columnas del FranceObservateur para designar un conjunto de países asiáticos, africanos y americanos que no formaban parte ni de un primer mundo capitalista ni de un segundo mundo comunista (Sauvy, 1952). La noción de Tercer Mundo se había instalado en el lenguaje periodístico y político francés desde fines de los años cincuenta, y había tomado mayor potencia a partir de 1961 con la publicación de Los condenados de la tierra de Frantz Fanon, cuando se expandió la creencia de que esos descolonizados alcanzaban plena condición de sujetos. El Tercer Mundo se expresaba a través de su propia voz, según postulaba Sartre en su célebre prólogo al libro de Fanon. (Jameson, 1997)

${ }^{17}$ Fuentes publicó esas crónicas como París: la revolución de Mayo (Era: México, 1968) 
en suma, de proteger su sentido de sí, su volundad de ser ellos mismos contra toda dominación. (Passeron, 2003)

Bourdieu y Passeron resistieron en esos años al presagio de una gran "mutación cultural" que convertiría al homo sapiens en un "cosmopolitecus", consecuencia de la homogeneización mundial producida por las industrias culturales. La idea de los micropoderes ponía de relieve la capacidad resistente de ciertos grupos y los intersticios como lugares de repliegue. En este mapa de la resistencia post-mayo, los extranjeros y particularmente los latinoamericanos multiplicaron su "capital resistente".

La actividad colectiva y anónima del Atelier Populaire tuvo mucho de esa desconfianza hacia la representatividad y las jerarquías asociadas que animó buena parte de "experimentos políticos de desclasificación" de estudiantes y trabajadores durante 1968, como las tomas de fábricas, los comités de acción y las Enquètes (Ross, 2002). En esa desidentificación, quienes pudieran considerarse representativos del Tercer Mundo parecen haber tenido un rol clave. Podría pensarse que constituían una suerte de garantía de autenticidad de esa experiencia fraterna.

Otro cronista del Mayo francés, un Nicolás Casullo de 23 años, recuperó treinta años más tarde las notas tomadas en su diario de viaje. ${ }^{18}$ El filósofo argentino señaló para mayo del '68 una operación discursiva medular, que lo despegaba de las izquierdas tradicionales.

Refundar la palabra como invención, o reinventar la furia de las palabras [...] contuvo la pretensión de sustraerle, al mundo de los vetustos 'reformadores', sustentos y excusas, aunque al precio de apostar por el camino del conflicto de las discursividades. Es decir, concluir con el engaño de las izquierdas salvo Gramsci - que habían visto en las ideologías corporizadas, en las representaciones de intereses, sólo un problema de mecánica de credos, de aguja hipodérmica, de publicismo, de superestructura que la ley de la historia resolvería en el momento del triunfo de los justos (Casullo, 1998: 27-28)

Casullo quedó particularmente impactado por los grafitis, una iniciativa de los situacionistas activos en Nanterre. Sin embargo, es posible argumentar que la operación discursiva a la que se refiere no fue sólo de la palabra, sino también de la imagen. Así como los grafitis operaron poéticamente sobre lo que podría llamarse el género de la pintada política (consignas en aerosol sobre las paredes callejeras), las serigrafías del Atelier Populaire lo hicieron sobre la tipología del afiche.

En una nota de abril de 1968 acerca de un negocio de posters en Saint Germain tapizado con los rostros del Che Guevara, Fidel Castro, "Lumumba,

\footnotetext{
${ }^{18}$ Durante un viaje por Europa estuvo en París entre marzo a junio de1968.
} 
el tío Ho", Casullo remarcaba el uso privado de esos posters: "El consumo de objetos de izquierda fue siempre novedoso, acompañante de las teorías. Irrumpe inesperado en las nuevas decoraciones, y además mucho más barato. Mercancía de caras prohibidas allá en el sur, seres oprobiosos para los poderes" (Casullo, 1998: 14-15). Las serigrafías producidas en el taller tomado de la Escuela de Bellas Artes prescindieron de esa iconografía tercermundista basada en retratos en buena medida tradicionales. Reinventaron imágenes de alto impacto y devolvieron los afiches políticos a la calle, transformados.

La autoría individual, patrimonio del mercado de arte, fue puesta en jaque. Y esa voz colectiva tendió a superponerse -en la mirada de Fromanger, GassiotTalabot y Rougement- con la figura del sujeto tercermundista que, como desearon fervientemente Gilles Deleuze y Felix Guattari en su Kafka. Por una literatura menor (1975), era necesaria y naturalmente colectiva, politizada, extranjera y marginal. En el marco de las jerarquías artísticas, el afiche era un género menor. Por un lado, su carácter publicitario lo retiraba de la arena de la autonomía. Además, su factura seriada y su circulación callejera lo dejaban a la intemperie, fuera del mundo de las bellas artes. El sistema de las instituciones culturales formaba parte de la sociedad que se pretendía combatir, y quienes participaron del Atelier Populaire apostaron a los poderes revulsivos de las prácticas culturales. Y al menos por estos pocos meses, ser foráneo sumó capital resistente a la extranjería artística.

\section{Referencias}

AA.VV. GRAV 1960-1968. Grenoble : Centre d'Art Contemporain de Grenoble, 1998. AA.VV. Figuration Narrative. Paris 1960-1972. Paris: Centre Georges Pompidou, 2008.

ATELIER POPULAIRE. L'Atelier Populaire présenté par lui-même. París: Usines Universités Union, 1968.

BARNICOAT, John. A concise history of posters: 1870-1970. New York: Harry N. Adams Inc, 1972.

BERTRAND, Romain. "Mai 68 et l'anticolonialisme" (2008). En AA.VV., Mai-juin 68. Paris: Les éditions de l'atelier, 2008, 89-101.

BERTRAND DORLEAC, Laurence. "Les artistes et la Révolution". En AA.VV., Les années 68. Les temps de la contestation. Bruxelles: Edition Complexe, 2000, 225238.

BESANÇON, Julien (comp.). Les murs ont la parole. Paris: Tchou, 1968.

CASSOU, Jean. En Mai 1968, affiches. Paris : Tochou, 1968.

CASULLO, Nicolás. París 68. Las escrituras, el recuerdo y el olvido. Buenos Aires: Manantial, 1998.

CHALUMEAU, Jean-Luc (comp.). La Nouvelle Figuration. Une histoire de 1953 à nos jours. Paris : Cercle d'Art, 2003. 
CHWAST, Seymour. Push Pin Graphic: A Quarter Century of Innovative Design And Illustration. San Francisco: Chronicle Books, 2004.

DEBORD, Guy (1967). La société du spectacle. Paris, Folio, 1992.

DELEUZE, Gilles y Felix Guattari (1975). Kafka. Por una literatura menor. México: Era, 2001.

DUPARC, Christiane, "La peinture passe aux actes", Nouvel Observateur n. 187, 12 juin 1968, 41-42, 1968a.

DUPARC, Christiane. "Les sud-américains ont pris Paris", Le Nouvel Adam n. 19, février 1968b.

FUENTES, Carlos. "La Francia revolucionaria: imágenes e ideas". En AA.VV, La revolución estudiantil. San José: Editorial Universitaria Centroamericana, 1971, 4748.

GASSIOT-TALABOT, Gérald. "Sur la violence dans l'art", Opus International n. 7, juin 1968a.

GASSIOT-TALABOT, Gérald. "Atelier Populaire", Opus International n. 9, décembre 1968b.

GERVEREAU, Laurent. "L'atelier populaire de l'ex-École des Beaux-Arts. Entretien avec Gérard Fromanger". En AA.VV., Matériaux pour l'histoire de notre temps n. 1112-13, Mai 68. Les mouvements étudiants en France et dans le monde, Bibliothèque de Documentation Internationale Contemporaine-Association des amis de la BDIC et du Musée. Nanterre, janvier-septembre 1988a, 184-191.

GERVEREAU, Laurent. "La sérigraphie à l'École des Beaux-Arts. Entretien avec Rougement". En Matériaux pour l'histoire de notre temps n. 11-12-13, Mai 68. Les mouvements étudiants en France et dans le monde, Bibliothèque de Documentation Internationale Contemporaine - Association des amis de la BDIC et du Musée. Nanterre, janvier-septembre 1988b, 179-183;

GILMAN, Claudia. Entre la pluma y el fusil. Debates y dilemas del escritor revolucionario en América Latina. Buenos Aires: Siglo XXI, 2003.

GUFFEY, Elizabeth. Posters. A global history. London: Reaktion Books, 2015.

JAMESON, Frederic (1984). Periodizar los '60. Córdoba: Alción, 1997.

KUISEL, Richard . "Détente. Debating America in the 1960s", en Seducing French: the dilema of Americanisation. Los Ángeles, University of California Press, 1993.

LE PARC, Julio. Entrevista a Julio Le Parc. En Ana Borón, Mario del Carril y Albino Gómez, Porqué se fueron. Buenos Aires: Emecé, 1995, 151-163.

LEENHARDT, Jacques; KALFON, Pierre. Les Amériques Latines en France. Paris, Gallimard, 1992.

LÉGER, Régis (dir). Cuba gráfica. Histoire de l'affiche cubaine. Paris : L'échappée, 2013.

LIAUSU, Claude. Aux origines des tiers-mondismes Colonisés et anti-colonialistes en France 1919-1939. Paris, l'Harmattan, 1982.

PARENT, François; PERROT, Raymond. Le salon de la Jeune Peinture. Une histoire 1950-1983. Paris : Montreuil, 1983.

PASSERON, Jean-Claude. "Quel regard sur le populaire?", Ville-Ecole-Intégration Enjeux, n.133, juin 2003. Vol.15, n²/julho-dezembro de 2016 $\begin{aligned} & \text { Brasilia } \\ & \text { ISSN- 1518-5494 }\end{aligned}$ ISSN (versão eletrônica):2447-2484 
PELLEGRINI, Mario (comp.) (1968). La imaginación al poder. París Mayo 1968. Barcelona, Argonauta, 1982.

PIGLIA, Ricardo. "Notas sobre El Facundo", Punto de vista a. 3 n. 8, Buenos Aires, 1980, 17, 1980.

PLANTE, Isabel. "La multiplicación (y rebelión) de los objetos. Julio Le Parc y la consagración europea del arte cinético". En Isabel Plante y Cristina Rossi, XIII Premio Fundación Telefónica a la investigación en historia de las artes plásticas en la Argentina. Buenos Aires: FIAAR-Fundación Espigas, 15-74, 2011.

PLANTE, Isabel. Argentinos de París. Arte y viajes culturales durante los años sesenta. Buenos Aires: Edhasa, 2013.

ROLLAND, Denis; TOUZALIN, Marie-Hélène. "Un miroir déformant? Les latinoaméricains à Paris depuis 1945". En Antoine Marès y Pierre Milza (dir.), Le Paris des étrangers depuis 1945. París: Publications de la Sorbonne, 263-291, 1994.

ROSS, Kristin. Fast cars, clean bodies: decolonization and reordering of French culture. Chicago: MIT Press, 1995.

ROSS, Kristin. May '68 and its afterlife. Chicago, The University of Chicago Press, 2002.

ROSSI, Cristina. "Julio Le Parc y el lugar de la resistencia". En ICAA Document Project Working Papers, n. 2. International Center for the Arts of the Americas at the Museum of Fine Arts: Houston, 43-50, 2008; disponivel em: http://icaadocs.mfah.org/icaadocs/enus/publications/documentsprojectworkingpapers.aspx

SAIEGH, Diana (dir). La casa argentina en París. Fondation Argentine 1928-1998. Ministerio de Cultura y Educación de la Nación, 1998.

SAUVY, Alfred (1952), "Trois mondes, une planète", L'Observateur, 14/8/1952.

SCHOR, Naomi. "The crisis of French Universalism", Yale French Studies n. 100. France / USA. The cultural wars. Connecticut: Yale University Press, 43-64, 2001.

SERVIDDIO, Fabiana (2013). Arte y crítica en Latinoamérica durante los años setenta. Buenos Aires: Miño y Dávila, 2013.

Tempest, Gene M., Anti-Nazism and the Ateliers Populaires: The Memory of Nazi Collaboration in the Posters of Mai '68. Berkeley University: thesis prepared for the B.A. in History, 2006; disponivel em: http://www.docspopuli.org/articles/Paris1968 Tempest/AfficheParis1968 Tempest.ht $\underline{\mathrm{ml}}$

TERÁN, Oscar. Nuestros años sesenta. Buenos Aires: El cielo por asalto, 1993.

VIOLEAU Jean-Louis. "L'expérience 68, peinture et architecture entre effacements et disparitions". En AA.VV., Mai-juin 68. Paris: Les éditions de l'atelier, 222-233, 2008.

WLASSIKOFF, Michel, Mai 68. L'affiche en héritage. Paris: Éditons Alternatives, 2008. 